\title{
Review on progress and challenges of the power generation systems at micro-scales
}

\author{
Junjie Chen*, Deguang Xu \\ School of Mechanical and Power Engineering, Henan Polytechnic University, Jiaozuo, Hen ina \\ *E-mail address: comcjj@163.com, comcjj@yahoo.com \\ The miniaturization of electro-mechanical devices, and the res fin $\mathrm{a}$ for $m$-power
}

\begin{abstract} generation (milliwatts to watts) with low weight, long life devices, ho fea to th cent $g$ cvelopment of the field of micro-scale combustion and power generation. The ry object this new field is to leverage the high energy density of fuels, specifically quid rocarbon ruels relative to batteries and all other energy storage devices other than nucl ussion, on gr decay. Some brief scaling arguments are given in this work, and more detaile efforts are referro A brief introduction to several of the fabrication techniques is presented in this ork. Hydrogen-based and some preliminary specialty fuel micro-fuel cells have been successfully veloped, an there is a need to develop reliable reformers (or direct conversion fuel cells) for id hydr carbons so that the fuel cells become competitive with the batteries. In this rark, the to sical issues related to micro-scale combustion and the development of thermocher for power generation will be discussed. Some of the systems currently being developed $11 \mathrm{~b} /$ ped, ongoing critical study issues under investigation, and other potential areas of do clopment discussed. Comments regarding the opportunities and limitations of each or echniqu are also presented where applicable.
\end{abstract}

Keywords: Micro-combustor $\mathrm{PQ}$ Micro-engine; Micro-rocket; Fuel cell; Microfabrication; Environmental ffect; Mio ower generation

\section{INTRODY CTIO}

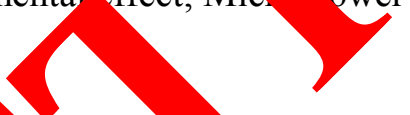

Demite th ret ty at the micro-power generation field is young, significant and ence aragi progre as been made, especially when one considers that only a few projects hav een funded to date. Several micro-combustors have been fabricated that appear to operat th goud combustion efficiency. Some of these combustors have been applied to energize moelectric systems to produce power. The system efficiency is currently too low, but the lipitation often appears to be in the thermoelectric component and not in the combustion process itself. Several turbines/engines have also been or are being developed, some of them currently producing positive power, although again with low efficiency [1]. Here the problem appears to be in fabrication and thermal management, which both limit the tolerances in moving parts (leakage, low compression ratio), and cause reduced efficiency of individual components (compressor, combustion chamber). Fuel cells are also being developed, and although not a combustion device, these chemical reaction systems have issues that are of interest to the combustion community [2]. Although hydrogen-based micro- 
fuel cells have been successfully developed and some liquid fuel (methanol/formic acid) based micro-fuel cells have been demonstrated, there is a need to produce reliable reformers (or further refinement of direct conversion fuel cells) so that they can be used with liquid hydrocarbons, and can become competitive with batteries.

It should also be mentioned that small-scale combustion has other useful applications than power generation and heat production for use in power cycles [3]. As an example, the positioning of localized combustion and meso-scale burner arrays to produce distributed combustion in large-scale gas turbine combustors, increasing the potential for inter-turbine reheat, and for premix or highly vitiated combustion, to reduce $\mathrm{NO}_{x}$ [4]. combustion can also have application in the area of flame ionization detectors a potent in applications that require rapid temporal or periodic pressure or temperature $p$. les.

Some of the technological issues related to micro-scale combustion the themi al devices for power generation are discussed below. A brief intrody ction man the fabrication technologies being employed follows. An introduction a lig oxide fucl cells (SOFCs), which can convert hydrocarbons directly at moder ce nmp tures ito useful electrical power, is given to follow as well. Lastly, a descy of man the systems currently in development are also presented and briefly dise sed.

\section{FUNDAMENTAL ISSUES}

\subsection{Thermal and heat transfer}

Some of the scaling issues involved in miv combustors can be understood by normalizing the conservation equations of mentum, energy, and species in terms of the characteristic length and paran eters the de $\mathcal{c}$, and analyzing their terms as the length scale is reduced. The enhancea th the intake manifold of the combustor is of particul conce in devices using pre-mixed reactants for combustion. While pre-heating the tants will sustaining combustion to scales smaller than the quenching distance, may lt in the auto-ignition of the mixture in the inlet port [5]. Thus, measures must b. coken to co. 1 the amount of heat that will be transferred to the incoming fuel/air mixty e (red ed volum ctric efficiency). Furthermore, heating of the reactants in the intake manio $\mathrm{vi}^{\mathrm{i}}$ also sult in a smaller mass charge in the combustion chamber due to the reduced den thus, educing the potential net power output of the device. The lower densicy $\mathrm{w}$ also ro $\mathrm{in}$ higher compression work per unit mass, and consequently lower or sy em efficiencies [6]. This is particularly critical in gas turbines since the power requir snts or we compressor determine their overall efficiency. In these cases, thermal managen becomes essential in order to reduce heat losses and increase the performance of the devices

Regarding thermal management, complex structures with highly insulating materials, vacuum gaps and/or complex thermal coatings may be needed to insulate and reduce heat transfer from high to low temperature regions [7]. However, thermal management is not only restricted to spatial temperature gradients, but also to transient heat transport. Very different characteristic times in the gas or the solid, or in the periodic heat fluxes from intermittent combustion may result in quasi-insulating conditions at the boundary [8]. For example, if the combustion time in a compression ignition engine is much shorter than heat transfer time 
through the engine housing, heat losses from the combustion reaction to the wall would be reduced because the lack of time to transfer the energy to the walls.

\subsection{Fluid dynamics}

The critical parameter that dictates fluid flow in power MEMS systems is the Reynolds number since the scale of the device and the fluidic throughput dictates the power level of the device. The small diameter of the channels for the reactant intake, the product exhaust, and the actual combustion chamber constrain the flows in micro-devices to relativall Reynolds number and hence, the majority of small-scale power systems are laminar issues related to viscous drag and mixing of multiple streams become crim for syste designers. Much work in fluidic handling has been carried out in regards lab-chip or micro total analysis systems ( $\mu \mathrm{TAS}$ ) in this size range. For many of the $p$ ver go 0 ing concepts, especially those described below, small changes in temper re, or exa npie, can significantly change the volumetric flow rate as can fluid-wall $j$ anctio that ar normally ignored in macroscopic flows [9]. The small channels also res in high ve gradients in the fluid, which as the aforementioned boundary condi ons cate, lead to high wall frictional losses, and high convective heat transfer cos in turn can result in large pressure losses, high heat transfer to or from t $t^{\prime}$ fluid to the wa, as well as enhanced diffusive mixing [10]. This next section will attemp o address is ues related channels where the flow is laminar $(1<\operatorname{Re}<2300)$, including pr re drops In channels, fluidic mixing, issues with the introduction of liquid fuels - micro-scar change and some microfluidic applications.

\subsection{Combustion}

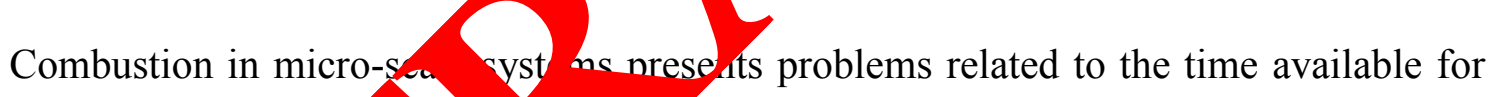
the combustion reaction to oour to tne possible quenching of the combustion reaction by the wall. Near-wall che ql kinetics, potential low wall temperature and radical depletion characterize the gas haso mbustion reaction [11]. Once again, the basic requirement for micro-combustio occur is the physical time available for combustion (residence time) must be large than the time re, aired for the chemical reaction to occur (combustion time). For gas-phas amb astron in flow systems such as in a gas turbine combustor, the residence time is determi, by the size of the combustion chamber and the flow rate of the reactant strear $\mathrm{th}_{\mathbf{h}}$ gh the $\mathrm{nber}$. For closed systems such as in internal combustion engines, in ad on to the size of the chamber, engine speed also determines the residence time. For cataly on the diffusion of species to the wall and species absorption/desorption at the wall determine the residence time. Since in general the residence time will be small in micro-com astors, it is important to have small chemical times to ensure completion of the combustion process within the combustor [12]. In general, small chemical times are obtained by ensuring high combustion temperatures, which in turn can be achieved by reducing the heat losses in the combustion chamber, preventing radical depletion at the wall, increasing the reactants' temperature, using stoichiometric mixtures, and using highly energetic fuels.

As engine size or combustion volume decreases, the surface-to-volume ratio increases, resulting in increased combustor surface heat losses and increased potential destruction of radical species at the wall [13]. These mechanisms will increase the chemical time and 
possibly prevent the onset of the gas-phase combustion reaction, or lead to quenching of an ongoing reaction. Thermochemical management techniques that can be used to overcome quenching are, among others, the use of excess enthalpy combustors, generating adiabatic walls by stacking planar devices in a symmetrical fashion (insulated temperature boundary condition), establishing high-temperature ceramic walls, and using surface coatings. The combustion reaction was optimized by using the enthalpy of the products to pre-heat the fuel air mixtures, in what is known as "Swiss-roll" combustor [14]. As a result of the enthalpy exchange obtained by recirculating the exhaust, steady combustion has been obtained with mixtures well below the normal flammability limits. Stable combustion has observed at temperatures below the expected homogeneous combustion tempe atures or fuels tested but above their normal catalytic temperatures. The concept of ta ulating $t$ exhaust to reduce the heat losses from the combustion region and to pr at th comi g reactants has been further implemented to attain combustion in thip tubes vith a cers smaller than the quenching distances that are reported in the literatue. as also be nased to develop micro-combustors [15]. Concerning the quenching dist aco, it vorth sentioning that the magnitude reported in the literature is considered ofte the limiting a for microscale combustion. This is a conceptual error, because the ench distance depends on the reaction rate, and thus on the temperature, species and cal cono (it is related to heat and radicals losses to the wall) [16]. The probl $\mathrm{m}$ of wall quencl $\mathrm{ng}$ can be reduced or prevented by increasing the wall temperature $(t)$ quenching distance is approximately inversely proportional to the square root of the temp ure), prey enting heat losses to the wall (adiabatic wall), or through catalytic activity- on the war

\section{FABRICATION}

MEMS fabrication teckm s y reader a good feel for acr of techmiques. Working with silicon based MEMS is advantageous as it all the existi howledge and foundries to be leveraged and most importantly it allow for coupling to traditional CMOS (Complementary Metal Oxide Semiconductor) (integrat circuitry) [17]. It is this coupling that allows for nearly instantaneous ensin control a d actuation. Rapid feedback sense and control is vital to the growth of the dr amic evices and systems due to the inherent disadvantages of scale and inertia [18]. Tra onal arface and bulk micromachining material removal (etching) and addit on position chniques, as well as relevant, less traditional techniques that have pro in he future growth of the Power MEMS field will also be covered.

con ravreation has its beginnings in the CMOS IC industry and only recently has the field MEMS in which mechanical elements are constructed of semiconductor materials using simi ar deposition and etching methods grown [19]. Silicon is the most common structural material due to its well characterized properties and fabrication tooling. MEMS fabrication occurs by first patterning the substrate by lithography and then depositing or removing material. Many of these steps are repeated to create 'features' on the wafer. Two types of micromachining have been identified, surface and bulk, and they are defined by the whether material is deposited onto the wafer (substrate) surface or three-dimensional features are etched into the bulk of the wafer [20]. Many modern MEMS features incorporate both surface and bulk micromachining into their processing. That being said, surface 
micromachining is more applicable for static and thermoelectric systems whereas bulk micromachining techniques are more applicable for thermo-mechanical systems.

Very often, the feasibility, design and fabrication of devices and systems become the primary focus of MEMS study and very little time or thought is given to assembly. Microassembly and micro-joining are critical to the production of systems as there is currently no good way to integrate several of the aforementioned techniques to create the system.

One of the major concerns with the emerging field of combustion power MEMS is the harsh environment to which materials are exposed. Thermal gradients and transients, corrosive fuels, elevated temperatures and pressures, oxidation, and combustio reactivity all can have significant influence on the semiconductor materials nat comp most systems [21]. This section will attempt to address many of these 1S and the implications toward the extended operation of these devices. Many ar suments ve be n given toward the low unit cost of MEMS devices and that these devic s will ot be ated for extended periods of time [22]. However, when individual compo ts pressu e sensors for example) are implemented into a larger device (such as a gas ine) $j$ order to effectively leverage the capability of mass fabrication and acted sent ation
elements, the ramifications of long-term exposure must be derst

Many power MEMS concepts are low Biot numb stems, hy serves to minimize thermal gradients within the solid structures [23]. H wever, many of /, systems utilize thin solid films as tribological elements, for electrical olation or $\mathrm{f} / \mathrm{r}$ chemical etch protection [24]. These thin films, not unlike bimetallic strips thermos ats, can generate very large thermal stresses in the materials due to at mic lattica efficient of thermal expansion (CTE) mismatch.

\section{CURRENT TECHN
Although the field}

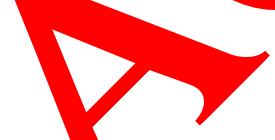

currently several ongo rojects to élop micro-scale combustors and power generators that are relatively 11 a ced. The ultimate objective of most of these projects is to develop a por ause, auton ays power-generation system using combustion with improvement nen $\mathrm{v}$ density ver batteries. There are also several approaches for micro air vehicle (MA pr ication but the majority of concepts are designed for the production of electricalnower . The projects have been grouped into four categories: micro-combustors, heat engh, rock and fuel cells. Although combustors and rockets are not power gen tors ry themserves, they can be used in conjunction with other devices (thermoelectric, piezo tric, mor fluid cycles, etc.) to produce electrical power, and are therefore included here bed of their combustion component. Fuel cells are not considered traditional combustion device however the oxidation of hydrocarbons in fuel cells and low temperature catalytic combustion are similar in nature [26]. The direct electrochemical conversion results in high efficiencies. The materials of construction and thermal stress issues are also similar for SOFCs and some catalytic designed systems. Furthermore, direct mechanical power generation is also of interest, and as mentioned above it is another of the assets of using combustion for power production. 


\subsection{Micro-combustors}

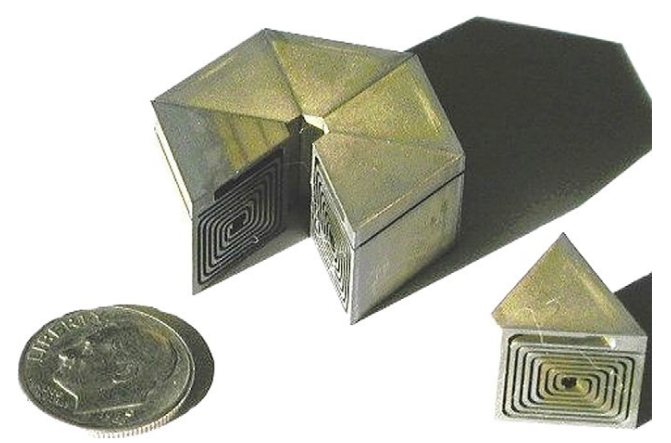

Figure 1. 3-D "Swiss-roll" type combustor.

Several micro-combustors and chemical reactors are cur ntly beins ved, either

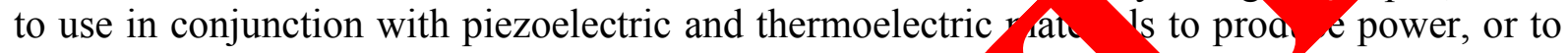
use as fuel reformers in fuel cells. The obvious advantag ' thes vices is that they don't have moving parts, but the problem generally lies ind low eft cy of the complete system. The Swiss roll approach has been used to evelop thermoelectric power-generation devices using micro-scale combustion. The goal of onney et al [27] is to develop a highly miniaturized, integrated, monolithically and batch-fa cated poy er generator with no moving parts, capable of powering devices down to MEM. Power production has been demonstrated, although to date with low e nev. New designs of these types of powergeneration devices have been recently pro ose on thermodynamic analysis that promise to provide better efficiencies. The cific proposed design consists of a section where heat is transferred to the $\mathrm{j}, \mathrm{g}$ react $\mathrm{nts}$ followed by another section that discards unconverted heat to the cold s ound gs. With is 3-D Swiss roll characteristics, the reactor shown in Fig. 1 appears to 1 LMS size devices because the heat losses are greatly reduced. Complig ation pres ly appears in the implementation of the thermoelectric unit. To date macro-s a nd meso- combustors have been fabricated and tested. Low temperature, self-su inea mbustion have been demonstrated in these larger reactors. An integrated comb r.SOFC ign has also been developed which utilizes the thermal integration of a Swi roll com astor design as a thermal management technique for SOFC operation.

\section{2.}

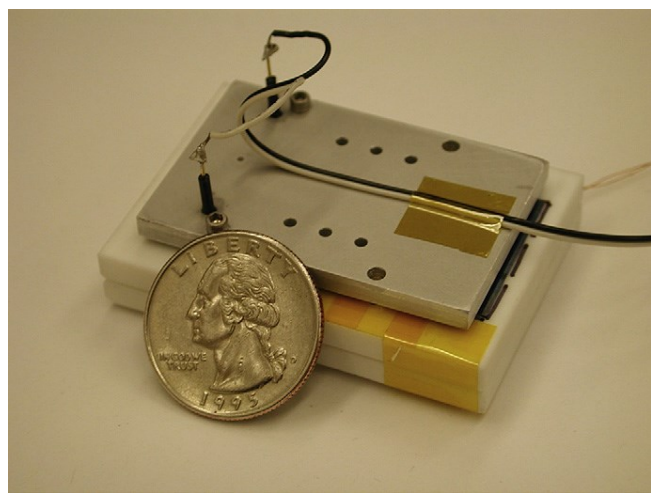

Figure 2. Photograph of $\mathrm{P}^{3}$ micro-engine. 
Because of the challenges these groups have faced in realizing micro heat engines based on rotating components. Richards et al. [28] have focused on developing a micro heat engine base on flexing components called the P3 Micropower Generator (Fig. 2). The engine, an external combustion engine, consists of a cavity filled with a two-phase fluid bounded by top and bottom thin membranes (Fig. 3). The one membrane acts as an evaporator. The other acts as an expander. A thermal switch controls the timing and duration of the heat addition and heat rejection. Mechanical power is produced as the expander membrane alternately expands and compresses the working fluid. At peak power output from the engine the power required to actuate the switch is a relatively small fraction of the power produced by the engin - Thus, it has been demonstrated net power out from this system consisting of a micro-co nbusto d micro-engine. A thin film of piezoelectric material is deposited on the expand nembrane obtain mechanical to electrical energy conversion. The engine and componen ave be integrated to demonstrate net power production when operating from a constant to erat re heat source at $60^{\circ} \mathrm{C}$.

\subsection{Micro-rocl}

Figure 3. Scher atic and tographs of MEMS fabricated micro heat engine.

Solid kets muve also been developed and fabricated using traditional MEMS technologies. h ct, man of the designs do not significantly differ from micro-machined airbag onera ther rocket projects include the development of improved nozzle des ins, th develop ent of liquid based micro-thrusters for micro-spacecraft applications, and simula effort given to directly address the issues of micro-propulsion. Solid fueled microrockets ha been developed for both space and terrestrial applications. The space thruster design fabucated at TRW and shown in Fig. 4 is a three-layer thruster developed for orbit and station keeping of picosatellites or micro-spacecraft and consists of a $\mathrm{Si}_{3} \mathrm{~N}_{4}$ burst diaphragm, a glass layer in which the lead styphnate propellants is housed, and a Si base layer with the resistive igniters. 


\subsection{Fuel cells}

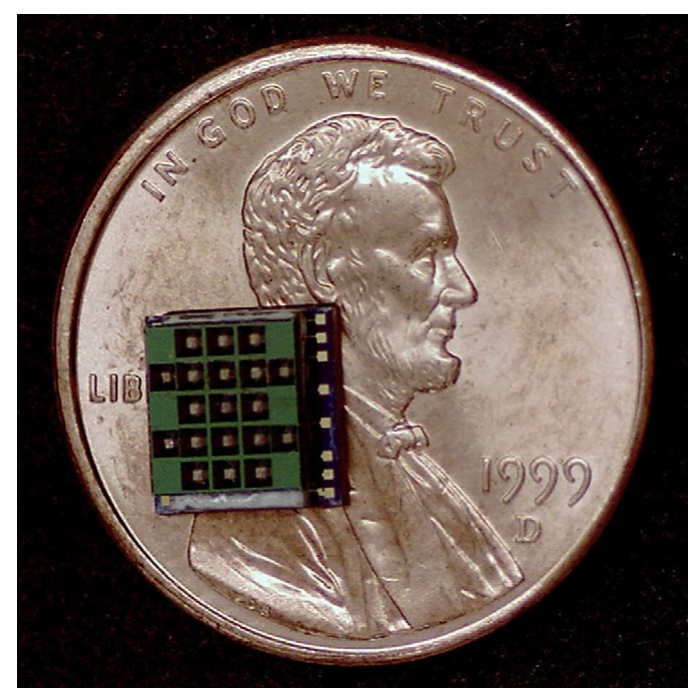

Figure 4. MEMS fabricated array of "Digital-Propulsio"

Fuel cells are electrochemical conversion de (on the anode side) and an oxidant (on the cathode electrolyte. The reactants flow into the cell, and the ro

ces. They produce electricity from fuel

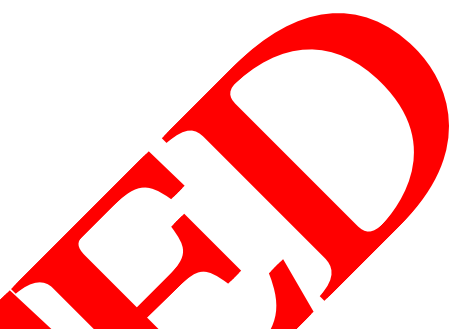
electrolyte remains within it [30]. Fuel cells operate vrtually continuously as long as the necessary flows are maintained. Fuel cells at dir. from electrochemical cell batteries in that they consume reactant from an exte a soy ce, which must be replenished: a thermodynamically open system 1 y contr t, batteries store electrical energy chemically and hence represent a thermod amic ly closec system. Typically, fuel cells need expensive precious materials in orde to fuel cells and catalysis would still not be realistic unless the precic as materia ading and cost diminished drastically.

Especially, ame g many ty, of fuel cells, solid-oxide fuel cells (SOFCs) have received considerab atten due to their high efficiency and fuel flexibility [32]. SOFCs offer a convenie it means of g aning electric power from conventional fuels, and given the absence of $\mathrm{m}$ ving $\mathrm{p}$ ts, may so be well suited to small-scale applications. Unlike proton exchange me ap (PEN fuel cells, SOFCs can use hydrocarbon fuels directly and do not require fuel pro acessi $g$ to generate $\mathrm{H}_{2}$ prior to utilization. Rather, $\mathrm{H}_{2}$ and $\mathrm{CO}$ are gene atea situ 6 by partial oxidation or, more typically, by steam reforming of the hy arbs a fuel in ne anode chamber of the fuel cell. SOFCs are all-solid electrochemical devic no liquid electrolyte with its attendant material corrosion and electrolyte manage problems. The high operating temperature (typically 500-1000 ${ }^{\circ} \mathrm{C}$ ) allows internal re, sming, promotes rapid kinetics with nonprecious materials, and yields high quality byproduct heat for cogeneration [33]. The total efficiency of cogeneration system can be $80 \%$-far beyond the conventional power production system.

In general, the SOFC consists of three components: (a) cathode for oxygen reduction; (b) anode for fuel oxidation; (c) electrolyte for oxide ions transportation. The function of the fuel cell with oxides is based on the activity of oxide ions passing from the cathode region to the anode region, where they combine with hydrogen or hydrocarbons; the freed electrons flow through the external circuit. 


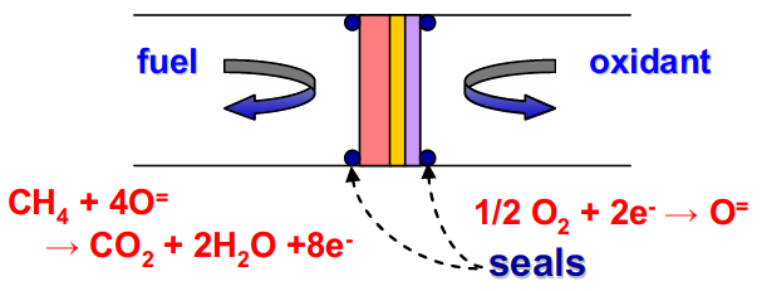

Figure 5. Schematic of a conventional dual-chamber SOFC.

Conventional SOFCs are operated with a split cell, dual-chamber cor quration: anode chamber supplied with fuel and the cathode chamber with air. The dual-ch ber SOF does not require catalytically selective electrodes, since the electrodes are exposed epar.te gas streams (Fig. 5), and is generally considered to be the technology choic for lar ocale stationary power generation. However, the dual-chamber configur (10, $v$ of wide applied due to the high cost $(\sim \$ 1000 / \mathrm{kW})$ which is mainly from the s aling iss of fy cells. In addition, it is not considered suitable for the portable applicat in which ant and rapid start-up and shut-down are necessary due to large inten 1 str during he heating and cooling processes resulting from the thermal expansion smatch cell components and sealant.

To a aress the caling issues, the concept of a single-chamber solid-oxide fuel cell (SCSOF sed by Wang et al. [34]. It is a sealant-free configuration with both electroc exposed to the same pre-mixed fuel-air mixture in one chamber (Fig. 6). An SCSOFC ma perate either using an oxygen ion conducting electrolyte, or one that conducts protons.

Thus, selection of the electrolyte type requires detailed knowledge of the ability of various anode and cathode materials to catalyze these reactions. Amongst conductors within each category, the criteria for materials selection are (a) high ionic conductivity, (b) low electronic conductivity, (c) good chemical stability, and (d) good processability, particularly in conjunction with electrode materials. Rare-earth doped ceria is one of the best choices amongst oxygen ion conductors; whereas rare-earth doped barium zirconate is the best amongst proton conductors [35]. The performance of the SC-SOFC depends on different 
catalytic selectivity of the anode and the cathode toward the fuel-oxidant mixture. By employing perovskite type materials, the SC-SOFC can achieve the comparable performance to the dual-chamber SOFC.

Because direct chemical oxidation of the hydrocarbon does not take place on the SCSOFC, the fuel and oxidant need not be physically separated and complications due to sealing are entirely eliminated. As a consequence, the SC-SOFC greatly simplifies the system design and results in excellent thermal and mechanical shock resistance. These features furthermore enable rapid start-up ( $<10 \mathrm{~s})$ and cool down. Unfortunately, however, the mixture of oxidant and fuel brings some safety issues because its susceptibility to explosion [36]. In addition the $\mathrm{SC}-\mathrm{SOFC}$ needs the extra heating-system for the ignition of fuel cell, rendering $\mathrm{t}^{\mathrm{C}} \mathrm{C} \mathrm{SC}-\mathrm{S}$ system complicated and the overall efficiency very low. Furthermore, SC-S $\mathrm{C}$ develop up to now can only use gaseous fuels directly, thereby limiting its range of finel th bility.

To overcome th itation on conventional dual-chamber SOFC and SC-SOFC, Kronemayer et al. [ ] pr sed an innovative concept of a direct-flame fuel cell (DFFC) operated withoy gas cha the operation principle of DFFC is based on the combination $r$ a fla e with a ,OFC in a simple, "no-chamber" setup. The flame serves as fuel-flexibl ial oxidat on reformer, while simultaneously providing the heat required for SOFC oneration the ombined system, flame and fuel cell are inherently coupled. For DFFC, $m$ the a of SOFC faces the flame and the cathode is exposed to the ambient air aty osphere ifference is produced between cathode and anode (Fig. 7). During the comb arocarbon fuels, a significant amount of useful gases, such as $\mathrm{H}_{2}, \mathrm{CO}$ and other hy carbons, is also produced due to the water gas shift reaction and partial oxidation even witho any catalyst.

There are a number of advantages in DFFC: (a) Simple setup: the DFFC can be operated in a no-chamber setup, such that the anode is simply held into the exhaust gases of a combustion flame, and the cathode breathes ambient air; (b) Rapid start-up: the flame heat release brings the fuel cell rapidly to its operation temperature; (c) Fuel versatility: since the intermediate species produced by the flame are similar for a wide variety of hydrocarbon fuels, the direct-flame fuel cell is highly flexible in fuel selection included gaseous (e.g. methane, ethane, propane, etc.), liquid (e.g. ethanol, butanol, kerosene, etc.) and solid (e.g. wood, wax, etc.) fuels. 
However, on the other hand, the DFFC concept has severe drawbacks: (a) Poor thermal shock resistance: the operating environment of a gaseous flame induces significant thermal stress to the SOFC. In general, the electrolyte layer is easy to crack at the high heating rate generated by the flame (typically $60{ }^{\circ} \mathrm{C} / \mathrm{s}$ ). This may lead to a rapid degradation of fuel cell performance or fractures of the material; (b) Coking: carbon coking is still an issue when the hydrocarbon fuels are employed. Carbon coking will block the gas diffusion inside an anode or even rupture the fuel cell; (c) Low efficiency and poor performance: an inherent property of DFFC is that a part of the fuel's chemical energy is consumed in the flame to sustain the fuel cell temperature [38]. For a typical burner, it is difficult to control the amount af fuel combusted versus the amount utilized for electrical power generation, thus colucits overall electrical conversion efficiency.

\section{CONCLUSION}

The field of micro-power generation is basically in a fo asibility e, ar a although significant progress has been made in the last few yo with so al important demonstrations, there are still a number of technologica roblu that nust be resolved before the field establishes itself. The approach onved to $/$ has been that of miniaturizing currently used large-scale devices, wh ch introduces ma problems related to fluid flow in micro-channels, heat and mass transpo in the micr-scale, combustion in small volumes, design, fabrication and diagnostics. Th colution f these problems requires fundamental study as well as manufacturip develop precedes the development of the micro-devices themselves. The study in nique to the development of combustion systems at the small scale include: mixing nd pung in low Reynolds number flows, simulation of distributed reactions, law tempe cure chemical kinetic modeling, investigative diagnostics, materials selection tav ation o bigh aspect ratio structures and complex geometries, assembly, testing cl racteriza ion. Initial investigations in this area have identified unique oscillator hen lo to better understanding of the role of the flow configuration substrato aterials must be able to sustain the high temperature, harsh chemical envir nm stress, a) wear due to combustion events. Emissions must be further investigate and nois ust be reduced to acceptable levels. The impact of fouling and coking in mic 0 -combustion actures and catalytic surfaces must be addressed, either through imp ed de ns and/or fuels selection. High-precision, high aspect ratio structures are necessary ovide as quate sealing for high compression ratios and to date, leakage and sealing lim cor bustion, and hence, system efficiencies. A repeatable and simple asse ibly hnique ast be developed in order to mass produce these devices and lastly, the den ne the tested and characterized to optimize their performance.

can speculate that some of these problems could be avoided if the approach to develop in power devices would be based on enlarging small (bio-related) systems rather than minia urizing large ones, often termed bottom-up manufacturing. However, it is likely that this approach will also have its own logistical problems. In any case, it is important to keep in mind that, because the specific energy of liquid hydrocarbon fuels is many times larger than that of secondary batteries, there is a lot of room for development of micro-devices that use combustion to produce power. Furthermore, given the current need for power (both electrical and mechanical) in the small scale the potential pay-off is very large.

As the combustion temperatures decrease in micro-combustors, and the temperature of the electrochemical reactions in fuel cells (SOFCs) increases, it seems that an area of 
intermediate temperature oxidation is emerging as the most relevant for small-scale power generation. In this regime, catalysis (either through deposited noble metals or through appropriate membranes) will play a major role over gaseous phase combustion.

In addition to power generation, the lessons learned as part of micro-combustion study can also be applied to components of larger systems such as ignition systems, fire safety applications, diagnostic tools, alternative power system architectures, and improved larger scale power-generation performance. Micro-combustion also has applications in a variety of fields, such as the generation of a large variety of future micro- and nano-materials including fine glass powders and nanoparticles, single walled nanotubes, as well as to depocitaxide, nitride and other materials.

The semiconductor materials used in the manufacture of MEMS distinct opportunities for the development of micro-combustors operational temperature, thermal and optical properties, however application to the fabrication of mechanical devices implies that a $\mathrm{n}$ must be resolved when used to build micro-power generators.

\section{References}

[1] Boyarko G.A., Sung C.-J., Schneider S.J., Catal zed combustion / hydrogen-oxygen in platinum tubes for micro-propulsion applicatic Institute 30(2) (2005) 2481-2488.

[2] Zhou J., Wang Y., Yang W., Liu J., Wa Z., Cen abustion of hydrogen-air in catalytic micro-combustors made of di onaterial. International Journal of Hydrogen Energy 34(8) (2009) 3535-3. 45.

[3] Wang Y., Zhou Z., Yang W. J., Liu , Wang Z., Cen K., Combustion of hydrogenair in micro combustors y th cat ytic Pt lic er. Energy Conversion and Management 51(6) (2010) 1127-1132.

[4] Shih H.-Y., Liu C. A comp tional study on the combustion of hydrogen/methane blended fuels fo a ro gas tur es. International Journal of Hydrogen Energy 39(27) (2014) 15103- 115.

[5] Yuasa S. Oshimi K., Nos Y., Tennichi Y., Concept and combustion characteristics of ultra- $w$ o con stors with premixed flame. Proceedings of the Combustion Institute $30(2)(2, \quad 2455-2,2$.

[6] ta T., h ara H., Tezuka T., Hasegawa S., Maruta K., Study on combustion and il nition ch acteristics of natural gas components in a micro flow reactor with a iperature profile. Combustion and Flame 161(1) (2014) 37-48.

[7] M. E., Fukushima N., Naka Y., Shimura M., Tanahashi M., Miyauchi T., Direct numo cal simulation of micro combustion in a narrow circular channel with a detailed kinetic mechanism. Proceedings of the Combustion Institute 35(3) (2015) 3421-3427.

[8] Liu Y.C., Xu Y., Avedisian C.T., Hicks M.C., The effect of support fibers on microconvection in droplet combustion experiments. Proceedings of the Combustion Institute 35(2) (2015) 1709-1716.

[9] Li Y.-H., Chen G.-B., Wu F.-H., Cheng T.-S., Chao Y.-C., Effects of catalyst segmentation with cavities on combustion enhancement of blended fuels in a micro channel. Combustion and Flame 159(4) (2012) 1644-1651. 
[10] Wan J., Fan A., Maruta K., Yao H., Liu W., Experimental and numerical investigation on combustion characteristics of premixed hydrogen/air flame in a micro-combustor with a bluff body. International Journal of Hydrogen Energy 37(24) (2012) 1919019197.

[11] Badra J., Masri A.R., Zhou C., Haynes B.S., An experimental and numerical study of surface chemical interactions in the combustion of propylene over platinum. Combustion and Flame 160(2) (2013) 473-485.

[12] Smyth S.A., Kyritsis D.C., Experimental determination of the structure of catalytic micro-combustion flows over small-scale flat plates for methane and propar - iuer. Combustion and Flame 159(2) (2012) 802-816.

[13] Kaisare N.S., Vlachos D.G., Extending the region of stable homogen combustion through forced unsteady operation. Proceedings of the Com rustion vit ate 31(2) (2007) 3293-3300.

[14] Sakurai T., Yuasa S., Ono Y., Honda T., Flame stability and cmssion aracte stics of propane-fueled flat-flame miniature combustor for ultra and Flame 160(11) (2013) 2497-2506.

[15] Sakurai T., Yuasa S., Honda T., Shimotori S., Hep noss reduction 1 hydrocarbon combustion in ultra-micro combustors for ultra micro gas turbines. Proceedings of the Combustion Institute 32(2) (2009) 3067-3073

[16] Ohiwa N., Ishino Y., Yamamoto A., Important ro of mo' 1 phase process in enhancement mechanism of micro pla narticle connoustion. Proceedings of the Combustion Institute 32(2) (2009) $199-200$

[17] Hosseini S.E., Wahid M.A., Inwestigation of blufi-body micro-flameless combustion. Energy Conversion and M nago ent 88( (2014) 120-128.

[18] Maruta K., Micro and nes al Proceedings of the Combustion Institute 33(1) (2011) 125-15 J.

[19] Bartrom A.M., a J. Guyen T.C Her J., Donovan A., Haan J.L., Optimization of an anode fabric tio meth for the alkaline Direct Formate Fuel Cell. Journal of Power Sources 2 29(0) (2013) 21, 38 .

[20] Azim $O^{1}$ uno M Tsuboi K., Kawahara N., Tomita E., Multidimensional CFD simulation syngas combustion in a micro-pilot-ignited dual-fuel engine using a von Icted ni al kinetics mechanism. International Journal of Hydrogen Energy $36(2)$ (2011), $793-13807$.

[21] S.-N., ark J.-S., Choi S.-H., Cho S.-H., Kim S.-H., Novel micro fuel processor for PE Cg with heat generation by catalytic combustion. Chemical Engineering Journal 113(1), (2005) 47-53.

[22] Hwang K.-R., Lee C.-B., Lee S.-W., Ryi S.-K., Park J.-S., Novel micro-channel methane reformer assisted combustion reaction for hydrogen production. International Journal of Hydrogen Energy 36(1) (2011) 473-481.

[23] Ganji H.B., Ebrahimi R., Numerical estimation of blowout, flashback, and flame position in MIT micro gas-turbine chamber. Chemical Engineering Science 104(0) (2013) 857-867. 
[24] Wan J., Yang W., Fan A., Liu Y., Yao H., Liu W., Du Y., Zhao D., A numerical investigation on combustion characteristics of $\mathrm{H} 2$ /air mixture in a micro-combustor with wall cavities. International Journal of Hydrogen Energy 39(15) (2014) 8138-8146.

[25] Jeon S.W., Yoon W.J., Jeong M.W., Kim Y., Optimization of a counter-flow microchannel reactor using hydrogen assisted catalytic combustion for steam reforming of methane. International Journal of Hydrogen Energy 39(12) (2014) 6470-6478.

[26] Moskovskikh D.O., Lin Y.-C., Rogachev A.S., McGinn P.J., Mukasyan A.S., Spark plasma sintering of $\mathrm{SiC}$ powders produced by different combustion synthesis routes Journal of the European Ceramic Society 35(2) (2015) 477-486.

[27] Kuo C.H., Ronney P.D., Numerical modeling of non-adiabatic heat-reci ting combustors. Proceedings of the Combustion Institute 31(2) (2007) 32 7-32

[28] Cho J.-H., Lin C.S., Richards C.D., Richards R.F., Ahn J., Ronne P.D., emons con of an external combustion micro-heat engine. Proceedings of the nh astion satute 32(2) (2009) 3099-3105.

[29] Lewis Jr D.H., Janson S.W., Cohen R.B., Antonsson E Sensors and Actuators A: Physical 80(2) (2000) 142 4.

[30] Yu X., Manthiram A., Catalyst-selective, scalab membraneless a aline direct formate fuel cells. Applied Catalysis B: Environmental 65(0) (2015) 63-67.

[31] Wang Y., Shi Y., Yu X., Cai N., Thermal shock istance ar d failure probability analysis on solid oxide electrolyte direct flame fu Journal of Power Sources 255(0) (2014) 377-386.

[32] Giddey S., Badwal S.P.S., Kulkarni A., I v nings C., A comprehensive review of direct carbon fuel cell technology, ess in E ergy and Combustion Science 38(3) (2012) 360-399.

[33] Bartrom A.M., Haan nate fuel cell with an alkaline anion exchange membrane. Journo of Power res 214(0) (2012) 68-74.

[34] Wang K., Zen ?., A. High performance direct flame fuel cell using a propane flame. Prog ings of th Combustion Institute 33(2) (2011) 3431-3437.

[35] Vogler , Hor shi M., Bessler W.G., Modeling, simulation and optimization of a nochamber oxide el cell operated with a flat-flame burner. Journal of Power Sonces 1 ro) (2rio) 7067-7077.

[36 Wan Y., Shi Y Ni M., Cai N., A micro tri-generation system based on direct flame fuel ential applications. International Journal of Hydrogen Energy 39(11) (2. 4) 5996-6005.

[37] Kron nayer H., Barzan D., Horiuchi M., Suganuma S., Tokutake Y., Schulz C., Bessler W.G., A direct-flame solid oxide fuel cell (DFFC) operated on methane, propane, and butane. Journal of Power Sources 166(1) (2007) 120-126.

[38] Choi W., Kwon S., Dong Shin H., Combustion characteristics of hydrogen-air premixed gas in a sub-millimeter scale catalytic combustor. International Journal of Hydrogen Energy 33(9) (2008) 2400-2408. 